\title{
A PERFORMANCE ARTE QUE VIROU POLVO: FLUTUANDO NAS ÁGUAS DAS ARTES EM CORPORALIDADES HIIBRIDAS E ININTELIGÍVEIS
}

\author{
Camila Olivia de Melo \\ Universidade Federal do Paraná \\ Regiane Ribeiro \\ Universidade Federal do Paraná
}

\begin{abstract}
Resumo: A performance arte, na contemporaneidade, tem-se mostrado uma potente ferramenta político-artística para visibilizar corporalidades em desacordo com o imperativo heterossexual. Foi realizada uma pesquisa etnográfica por dois anos em uma casa de cultura de Curitiba-PR, e nela encontramos misturas corporais. A performance naquele contexto estava sendo entendida como um polvo, uma mistura de performance e polvo. Descobrimos uma potência comunicativa para a livre expressão de gênero, para desestabilizar a matriz coerente de gênero ou, no mínimo, uma fuga de seus modelos normativos e rígidos. O corpo em tentáculos intercambiava por diversas linguagens artísticas para emitir mensagens que pudessem comunicar a própria vida, visibilizar a própria atitude queer.
\end{abstract}

Palovras-chave: performance arte; comunicação; queer.

\section{Introdução}

Este artigo é baseado nas descobertas mais frutíferas da dissertação de mestrado intitulada Do palco ao asfalto, dos meios aos corpos: observando os tentáculos da performance-polvo como estratégias comunicativa-educativa, defendida pela Universidade Federal do Paraná em 2014. Foi com a investigação etnográfica - realizada durante dois anos em uma casa de cultura autônoma e artística da cidade de Curitiba-PR chamada Selvática - que encontrei uma metamorfose nas artes. Durante as observações participantes, encontrei uma maneira diferente de conceituar a performance arte, essa

Copyright $\odot 2015$ by Revista Estudos Feministas. 
atitude corporal que traz à pele mensagens críticas e autobiográficas. A performance no contexto da pesquisa estava sendo chamada de polvo, performance-polvo.'

Nesse sentido, o foco do artigo será a apresentação das impressões/reflexões formuladas a partir das análises de entrevistas narrativas. Apesar de as entrevistas terem sido feitas com três integrantes performers da Casa Selvática, para este artigo foi preciso recortar e trazer duas delas: Guilherme Ossani (aqui tratada como "a" Gui) e Stéfano Belo (Théo, o Belo). Entretanto, a interlocutora Gui terá mais ênfase, com maior descrição das análises, trechos de entrevista e anotações de campo, enquanto Théo aparecerá apenas nas articulações do conceito performance arte.

A mais forte impressão, para não dizer conclusão, que ficou da pesquisa foi a reflexão de que a performance arte na contemporaneidade pode atingir potência crítica cotidiana, biográfica e artística ao mesmo tempo. Isso quer dizer que as performances que foram observadas em Curitiba dizem respeito à mescla do palco e da vida, uma aquarela em que a arte acontece ao mesmo tempo no palco, no asfalto e na carne. Foi essa mistura de territórios que possibilitou pensar essa expressão corporal como polvo, pensar a performance arte com a criação de uma expressão nova: performance-polvo.

Assim, proponho aqui a seguinte organização textual em dois momentos: o primeiro é abrir meu diário de campo em que mesclo entrevistas e sensações a respeito de minha interlocutora "a Gui", pois é com seu relato que encontro força investigativa ao que a filósofa Judith Butler ${ }^{2}$ chama de matriz de inteligibilidade de gênero; e mais, é com sua identidade flutuante de gênero que percebo a potência político-cotidiana que a performance arte tem ocupado na contemporaneidade. Essas reflexões nos fazem tomar a própria performance arte como espaço de comunicação. Com isso, me refiro ao corpo como produtor de mensagens próprias, expressando sua subjetividade.

No segundo momento, exploro o conceito de performance arte com o nova-iorquino Marvin Carlson ${ }^{3}$ e com RoseLee Goldberg, ${ }^{4}$ confrontando-o com as vivências e experiências das próprias interlocutoras de pesquisa, para assim observar algumas especificidades que o campo nos trouxe.

A comunicação em uma perspectiva cultural, portanto, é fundamental para pensar os processos comunicativos acontecendo no momento de produção da performance. Encontramos, no cotidiano de nossas interlocutoras, pistas para afirmar que a performance arte, a performance-polvo, tem potência comunicativa para a livre expressão de gênero, para desestabilizar a matriz coerente de gênero ou, no mínimo, uma fuga de seus modelos normativos e rígidos.

Dentro de tal matriz de inteligibilidade, haveria uma continuidade entre biológico/ gênero/sexualidade/prática sexual, o que poderia ser entendido como, por exemplo, vulva/ mulher/feminino/heterossexualização do desejo. Isso constituiria o que Butler ${ }^{5}$ chama de gêneros coerentes. $O$ gênero feminino apenas estaria coerente se estiver sendo exercitado em um corpo biologicamente instituído como mulher, que, por sua vez, precisaria praticar seus desejos dentro do modelo heterossexual.

\footnotetext{
${ }^{1}$ A expressão performance-polvo está sendo utilizada no texto como um neologismo ou uma expressão nova e por isso leva itálico. A expressão foi criada a partir de minha pesquisa de mestrado desenvolvida no PPGCOM na UFPR que, unindo as duas palavras demonstra como a performance pode unir diversos elementos, objetos e linguagens em uma única corporalidade.

2 Judith BUTLER, 2012.

${ }^{3}$ Marvin CARLSON, 2004 e 2011

${ }^{4}$ Roselee GOLDBERG, 2006.

${ }^{5}$ BUTLER, 2012.
} 
Se pensarmos com a filósofa que o sexo é sempre gênero, a própria denominação feminino e masculino é em si um dispositivo regulatório. Isso porque para Butler ${ }^{6}$ o sexo é um conjunto de normas regulatórias que regulam e determinam o que se pode ou não se pode ser/estar a partir do gênero marcado pela norma, e essa marca possibilita apenas o feminino ou o masculino. Obedecendo as normas da feminilidade, por exemplo, o sexo estaria assim materializando-se nos corpos. Mas, e quand o o corpo não reitera a matriz - essa mesma que regula o sexo-gênero -, deixando de repetir e reiterar o que o dispositivo sexo exige? A esse corpo resta apenas a não compreensão; ele se torna, assim, inviável, ininteligível, um corpo em abjeção.

O 'sexo' é um construto ideal que é forçosamente materializado através do tempo. Ele não é um simples fato ou a condição estática de um corpo, mas um processo pelo qual as normas regulatórias materializam o 'sexo' e produzem essa materialização através de uma reiteração forçada destas normas. O fato de que essa reiteração seja necessária é um sinal de que a materialização não é nunca totalmente completa, que os corpos não se conformam, nunca, completamente, às normas pelas quais sua materialização é imposta.

Dessa maneira, em certo grau, todos/as nós carregamos uma certa abjeção. Isso porque a matriz regulatória não é completa, nem integralmente eficaz. O corpo normativo se materializa a partir do que não pode ser, o corpo em desenho padrão de espessura é marcado a partir daquele que não o é; por exemplo, o corpo gordo. Os símbolos determinados pela norma como de feminilidade seriam marcados a partir dos que não o são: barba, cavanhaque ou pelos. Corpos que importam existir são escolhidos a partir dos corpos que não importariam existir; são, portanto, pontuados com base no que a norma regulatória do sexo-gênero exclui. ${ }^{8}$

Com a noção do imperativo heterossexual, é possível visibilizar justamente as práticas que são rivais e subversivas em relação à matriz de coerência do heteropensamento. A heteronormatividade faz emergir teoricamente os corpos queer - incoerentes, descontínuos, com identidades de gêneros criativas - desordenando o culturalmente compreendido. Há sempre o que da matriz regulatória escapa, o que ao normal resiste.

Nesse sentido, é através das corporalidades que escapam da norma, dos corpos ininteligíveis, aqueles que são metade molusco, metade planta - como preferem ser identificados - que traçamos nossas mais importantes impressões-reflexões a respeito da performance arte contemporânea. No contexto da pesquisa, ao visibilizarem seus próprios corpos de identidade híbrida de gênero, tornavam possíveis outros modos de existência.

Por fim, trago no meio do texto as minhas imagens-colagens - as quais tenho chamado de Arte-fanzine - que produzi durante a pesquisa de campo. Posso dizer que expressam imageticamente a minha experiência etnográfica na Casa Selvática. Lá, estive em contato com diferentes maneiras de viver, com corporalidades tão "absurdas e abjetas". 9

\section{A Gui: "quero costurar-me novamente, quero ser quem eu quiser"}

A Gui foi a primeira pessoa da Casa Selvática com quem conversei sobre performance arte, com quem dancei a noite toda e com quem criei um laço de curiosidade-afetiva. Algo

\footnotetext{
${ }^{6}$ Judith BUTLER, 2000

7 BUTLER, 2000, p. 154

8 BUTLER, 2000.

${ }^{9}$ As palavras marcadas com aspas a partir deste ponto do texto fazem referência ao vocabulário nativo encontrado na pesquisa de campo.
} 
comunicativo naquele corpo me chamava atenção. Um corpo esguio, com as costas alinhadas, nariz fino e lápis preto nos olhos, vestindo desde o brilho a camisas tropicais. Olhos que observam por cima dos ombros, um corpo que balança a cabeça quando solta uma gargaIhada, uma árvore com frutas híbridas, uma trança entre os reinos animal, vegetal e os gêneros.

Natural de Lages-SC, na época de nossa conversa, Gui tinha 24 anos e já era formada em Artes Cênicas pela Faculdade de Artes do Paraná (FAP). Estava com muitas vontades, experimentando-se com as produções das performances, discotecando nas festas e também com desejo de ingressar em um programa de mestrado. Mais recentemente, em nossa última conversa, estava com uma vontade louca de passar um tempo nos Estados Unidos. Sempre com essa vontade de não ter planos, de acionar seu devir matilha ${ }^{10} \mathrm{e}$ percorrer os mais variados campos do mundo. A Gui é uma energia mutante, cíclica, rodopiando por entre meus canais de recepção.

Na tarde em que nos encontramos para a entrevista, ela disse-me por SMS que tinha "acordado linda"," e acordou mesmo. Chegou alegre e receptiva para nossa conversa. Suas palavras entraram como abelhas em meus ouvidos, trêmulas e raivosas. Havia gestos nas mãos, dedos em anéis, olhos relampejantes, além daquela estética arrepiante aos modelos coerentes de gênero no próprio corpo de Gui, pois faz questão de dizer que mistura-se ao popular, que mescla elementos, em suas próprias palavras, "feminilizantes".

Para descrever a Gui um pouco mais, ela é de um corpo ornamentado, do "frufru e do rococó", que, aproveitando símbolos culturais Latino Americanos, se refaz. Gui é uma bordadeira de si mesmo. Comunicando a si mesma, ela foi costurando, durante a entrevista, as imagens mais ricas em detalhes, ilustrando sua subjetividade que pulsa ali, no movimento de seu corpo. Enquanto prestava a máxima atenção nas frases que me dizia, senti-me como em um embalo na dança. Quando suas palavras me moviam de um lado para o outro da sala, me senti por vezes no mar. Estava em um oceano de identidades, com uma infinitude de possibilidades de existência.

Porém, foi durante nossos encontros não marcados, reuniões para cozinhar pratos da culinária vegan ${ }^{12}$ ou em festas particulares que - com maior sensibilidade - pude captar algumas pistas sobre a performance diluída no cotidiano e também a enxergá-la como um polvo. Segue anotação de campo que realizei em um desses encontros não marcados:

Não gosto muito de falar sobre queer, sabia? [silêncio] Prefiro escrever cuer (com cu mesmo para brincar mais com a palavra!) $A$ Gui diz que a performance para ela é como uma intersecção de linguagens, um polvo que se alimenta de diversas linguagens artísticas para fazer uma outra coisa. Percebo que cada pedaço do seu corpo se movimenta, náo só as pontas do casaco. Seus cabelos em cachinhos, dedos rodando entre eles. Anéis dourados, colar de tesourinha de

\footnotetext{
${ }^{10}$ Com devir matilha tomo emprestada uma das expressões que Guilherme Ossani usava casualmente. A Gui utilizava essa expressão quando queria afirmar a vontade de estar em um grupo em que o cuidado e a vigília fossem realizados por todas as pessoas pertencentes a essa matilha. Mais que isso, queria expressar sua vontade de ser menos indivíduo e mais grupo.

"Adoto, nesse momento do texto de Gui, tanto o artigo "a" como o "o" para seguir o movimento de sua própria denominação. Por vezes, refere-se a si com os artigos tidos femininos e, em outros, com os masculinos. ${ }^{12} \mathrm{O}$ veganismo é uma atitude política em não apoiar nem consumir (principalmente, vestuário, cosméticos, medicamentos e alimentos) nenhum produto de origem animal. O termo foi cunhado em $1944 \mathrm{em}$ uma reunião da "Sociedade vegetariana" nos Estados Unidos e é parte da palavra

vegetarian-vegan. A atitude vegan também está associada ao questionamento dos testes realizados em animais e principalmente ao especismo, machismo e sexismo. Nesse sentido, o veganismo está atrelado a uma rede de questões feministas, colocando em evidência a objetificação tanto dos corpos de mulheres como de animais não humanos.
} 
costura, botinha e uma bolsa pequena de lado, preta gracinha. Me sinto como nas festas pós show/festival de rock dos 90 's, principalmente o lesbocore da banda de meninas L7, porque todas aqui possuem um 'monster in me' - como na própria música da banda.'

Os detalhes do figurino que veste nas performances, nos objetos de cena, no botão da camisa ou nos brincos de pressão dourados que usa, são parte da produção de suas ações comunicativas. Digo detalhes, pois sua construção estética é rica em pequenos ornamentos, por exemplo, um cachinho de seus cabelos caindo no olho esquerdo que está contornado de lápis preto, ou seu pingente de tesoura "daquelas antigas que você encontra em armarinhos", como me deu a dica para encontrar uma similar. Esse figurino detalhado de Gui inspirou-me a representá-la imageticamente através da colagem, como pode ser visualizada na Figura 1. Essa construção minuciosa de si para o cotidiano assim como para as performances também dizem respeito ao que Gui chama de uma "comunicação sutil" em seu trabalho. Para Gui, sua comunicação sutil seria aquela indireta, em que é preciso pensar várias vezes para entender do que se trata, pois "está ligada ao processo pessoal" como me explicou.

E para Gui, tal processo pessoal está ligado a um acontecimento bem marcante durante sua infância, em suas palavras conta que, ainda criança, já se comunicava de maneira a extravasar, desestabilizando os códigos do guarda-roupas de sua família. Ela relata na entrevista a respeito do dia em que foi "tomada pela saia": vestiu uma saia de sua irmã e, através desse objeto, como um canal de expressão, saiu gritando e dançando, como afirma "meio histérico e absurda [...] a sensação era de estar sendo possuída e tomada por aquela saia". Em estado de euforia, abriu a porta do apartamento e saiu pelo corredor, dançando, gritando e, com isso, chamou, obviamente, a atenção dos vizinhos/as, que saíam em suas portas para ver o que estava acontecendo. No corredor, lembra ainda, havia algumas grades de segurança e Gui se agarrou nelas e, jogando a cabeça de um lado pro outro, começou a chacoalhar as grades e fazer "um saracoteio bem possuída e absurda".

É com essa subjetividade abafada e com esses espasmos a tirar algo que sufoca, que Gui

Figura 1: A Gui - quero costurar-me novamente. Vontade de tirar uma coisa que sufoca.

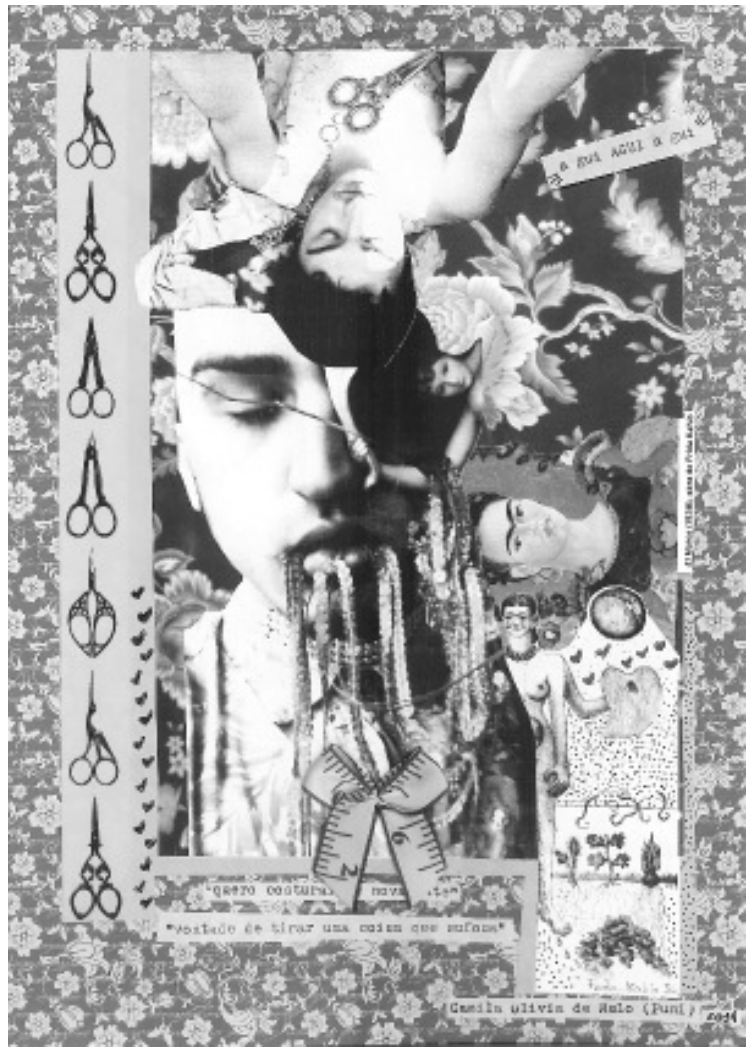

Fonte: Camila Olivia de MELO [Camila Puni], 2014a.

${ }^{13}$ Notas do diário de campo, set. 2013. Festa secreta, para exibição do web-documentário Trans*Lúcidx. 
ansiava por comunicar essa vontade de expressar livremente suas identidades de gênero. Foi com esse tom que Gui começou a entrevista contando as motivações para a produção de seu trabalho. É o que nos conta, referindo-se ainda a esse acontecimento:

E essa vontade de tirar uma coisa que sufocava... que naquele caso era bem uma questão de gênero e de expressão de gênero que era tirada de mim. Porque, eu até já comentei com a minha mãe.... todo o meu corpo foi sendo violentado assim... e eu lembro que meus pais falavam que eu não podia dobrar a minha mão, eu dobrava muito a minha mão... eu rebolava. Eu sempre ia sendo podado... meu corpo ia sendo podado e amputado.

Refletindo com Butler ${ }^{14}$ a partir da matriz de inteligibilidade social de gênero, é possível fazer uma ponte com as angústias de Gui. Quando nos conta da impossibilidade de expressar o gênero feminino, é possível pensar que, aos olhos dos vizinhos/as, da família e de seu círculo social, algo se apresentava incompreensível, incoerente ou desajustado. Esse "algo" perturbador no corpo de Gui mostra-se com os movimentos em seu próprio corpo que não Ihe eram permitidos, evidencia-se com os objetos que, para o culturalmente inteligível, eram proibidos e ameaçadores à sua masculinidade. É justamente em relação a essa masculinidade - esse conjunto de símbolos associados ao universo masculino -, que Gui afirma nunca ter se "encaixado bem". Por desajuste, restou-lhe castigo e correção, cortando-lhe o que de feminino havia em seu espontâneo movimento.

As marcas de gênero dentro da matriz de coerência vão sendo assim cotidianamente "embutidas no corpo", ou seja, enquanto as marcas da masculinidade eram forçosamente colocadas na subjetividade de Gui, as marcas da feminilidade foram sendo dolorosamente arrancadas de seu corpo. Ao corpo de Gui, a norma de gênero não permitiria ou tornaria possível jogar com os símbolos do feminino, pois, por mais absurdo que isso seja, a sua construção orgânica representava o que se entende por um corpo de homem e, ao corpo com pênis, está proibida qualquer maneira de vivência-experiência com o feminino.

Com essa perturbação e desajuste à matriz de gênero, Gui percebe-se como um "homem Frida", que, como ela diz também, "'trabalha sobre sua própria carne". Isso porque as barreiras entre vida e performance não podem ser exatamente encontradas. O movimento de costurar em sua própria carne ${ }^{15}$ parece aqui também uma ação de descosturar o que a heteronormatividade pretende fixar nela, ou até o que repetidamente está sendo embutido em seu corpo. E, para isso, além das linhas, agulhas e tesourinha, Gui resgata, dentre as "miudezas" que constituem a costura da sua performance, o que chama de "mordaça de ouro". É com ela que representa em suas apresentações performáticas tudo o que foi e ainda é impedido de falar, dizer ou morder.

Nesse sentido, ouvindo a narrativa da Gui, posso observar que é nas performances - naquele momento de "possessão e bruxaria", como chama - que ela comunica estar sendo o que quiser, quantos quiser e o que quiser estar. Essa seria uma das aspirações de Gui justamente por ter passado tanto tempo sendo "podado". Produz e pensa seu "estado performático" como um trabalho de "alteração da própria vida", uma costura de si em busca da corporalidade que nunca lhe foi permitida, mostrando assim as motivações de suas produções. Segundo ela mesma:

[...] lembro até da imagem do Frankenstein, tenho até uma obra que é um pouco isso... de resgatar essas partes e me recosturar. E gosto muito da ideia do bordado de me re-bordar fazer uma nova carne assim... De pedaços que me foram tirados.

14 BUTLER, 2012

${ }^{15}$ Podemos visualizar literalmente Gui no vídeo performance Falópia (2012), costurar literalmente em sua pele um botão. Com a agulha entrando na pele, seu sangue vai costurando em si o que lhe foi podado. É possível acessar a vídeo performance em http://vimeo.com/65425883.

244 Estudos Feministas, Florianópolis, 23(1): 239-248, janeiro-abril/2015 
À Gui posso afirmar, a partir de minhas observações de campo e das conversas de corredor, que sua performance arte aquarela as limitações entre palco e vida. E é com essa maneira particular de movimentar o seu corpo-polvo, essa maneira específica de chacoalhar o seu tronco de árvore frutífera, que procura resistir e desestabilizar o que de estável obriga a heteronormatividade. Vai assim costurando suas produções performáticas com detalhes de sua própria existência, irradiando e mordendo de volta os pedaços de um corpo podado e amputado. O que pulsa do corpo de Gui é uma comunicação que utiliza como estratégia a arte performance, uma comunicação cotidiana, uma arte performática em formato de polvo que transgride as barreiras entre palco e vida.

\section{Performance-polvo}

O conceito de performance arte foi delineado teoricamente de forma simultânea à formação dos Estudos da Performance. O conceito é marcado histórica e teoricamente como um "fenômeno americano" desenvolvido e praticado fortemente nos Estados Unidos entre as décadas de 1960 e 1970, principalmente, entre os movimentos de contracultura, feministas e gay-lésbicos. ${ }^{16}$

Trazendo o olhar às ações performáticas contemporâneas, tendo em mente a pergunta "o que é performance?", Carlson ${ }^{17}$ diria que a performance é um fascinante processo de "autoexperimentação" e "autorreflexão" tanto para as questões culturais como pessoais. Tateando também uma descrição-definição, Goldberg ${ }^{18}$ nos conta que a performance, ao longo do tempo, tem sido um "meio ou um canal" para dirigir-se a um público, levando críticas principalmente às concepções hegemônicas de arte e cultura. Tal obra, como a autora chama, pode ser produzida como um "espetáculo" (solo ou grupo) - o que permite agregar a ela elementos para iluminação, figurino e música simples ou sofisticados - e também como criação do próprio performer. Escandalizando e chocando a plateia no teatro ou na esquina, no café ou no bar, a performance apresentaria, assim, criticidade.

Dito isso, podemos refletir sobre o que encontramos no relato de nossas interlocutoras de pesquisa. Para Théo, o Belo, haveria uma ligação afetiva entre sua vida e suas produções, pois seria a performance o elo, a continuidade entre os conceitos estudados e a produção da performance assim como para Gui, que não encontra barreiras dicotômicas entre o palco e vida. Quando perguntei sobre suas ações performáticas, Gui disse-me: "de qual performance você quer saber? Porque estou fazendo várias delas nesse momento."

Por certo, a própria construção da performance mescla-se às questões pessoais de Théo. Como afirma, "é autobiográfico!" e, mais que isso, no momento da ação performática, nesse ritual quase místico, o que estiver para acontecer acontecerá naquele momento, sem avisos prévios ou introduções da apresentação. Nesse sentido, a performance arte, como Théo a descreve, é "o momento do tempo presente".

A respeito da questão relativa à autobiografia, é possível encontrar em Carlson ${ }^{19}$ uma passagem que caracteriza a performance como "autobiográfica". Contudo, uma descrição mais subjetiva e ritualística, quem nos oferece é o próprio Théo. Seguem os trechos, primeiro o de Carlson, ${ }^{20}$ em seguida da interlocutora Théo, o Belo.

Quase por definição, os seus praticantes não baseiam o seu trabalho em personagens previamente criadas por outros artistas, mas nos seus próprios corpos, nas suas autobiografias, nas suas experiências específicas numa dada cultura ou no mundo,

16 CARLSON, 2004 e 2011

${ }^{17}$ CARLSON, 2004, p. 216.

${ }^{18}$ GOLDBERG, 2006, p. 8.

${ }^{19}$ CARLSON, 2011.

${ }^{20}$ CARLSON, 2011 , grifo nosso. 
que se tornam performativos pelo fato de os praticantes terem consciência deles e por os exibirem perante um público. ${ }^{21}$

Porque o teatro tem essa coisa do ritual, sabe? do... momento em que parece que TUDO vai acontecer. O momento do tempo presente. Que é aqui e agora, tudo está acontecendo. No momento presente tudo acontece. E na performance é esse momento presente que se dilata em uma outra perspectiva de magia mesmo...de...de arte!

Por fim, é importante ainda retomar a passagem em que a Gui descreve uma particularidade da performance: uma ação corporal descrita-imaginada como um polvo, que segura em seus tentáculos diversos objetos e com eles torna possível expressar as suas próprias mensagens, como um manifesto de si. Assim, a perfor-

Figura 2 - Obra "capa" da dissertação de mestrado de Camila Olivia de Melo [Camila Puni].

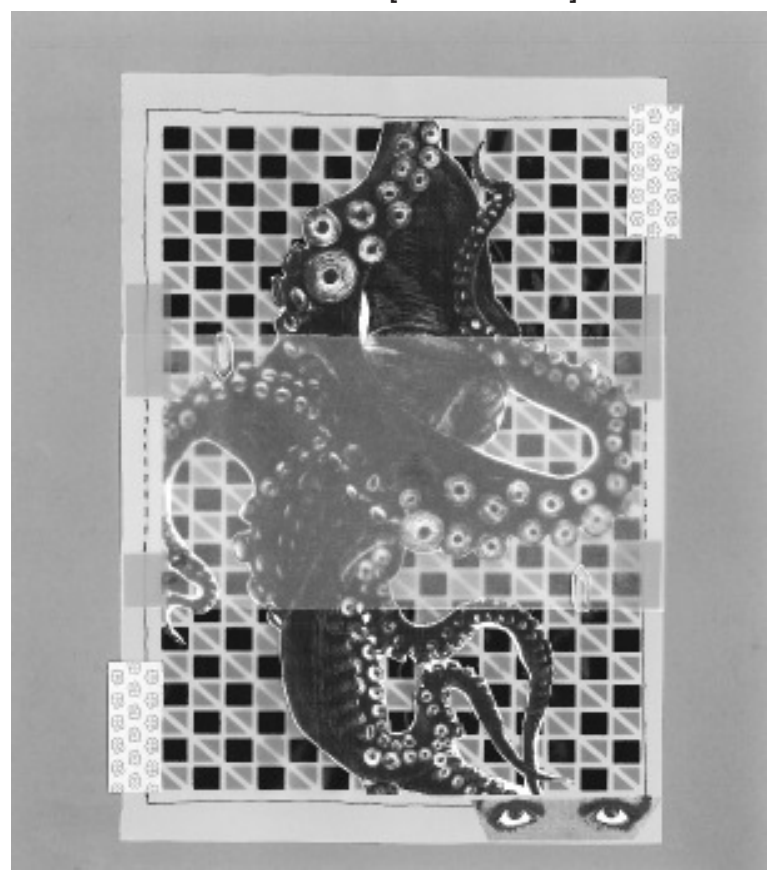
mance seria "uma intersecção de linguagens, um polvo que se alimenta de diversas linguagens artísticas para fazer uma outra coisa". Nesse sentido a Figura 2 pode mostrar, através de suas camadas de recortes e mescla de materiais, a noção de performance polvo que Gui conta em seu relato. A performance-polvo tornase então, na perspectiva de Gui, uma maneira de trabalhar na "própria carne", expressando - seja no palco, no asfalto ou na vida uma ação de sua própria existência. O corpo seria, então, a sua própria obra. Tomando o corpo como ferramenta de emissão de suas mensagens, haveria uma capacidade de "aderência", da mesma maneira que o polvo. Isso porque um polvo reúne imageticamente diversas habilidades e, assim, ilustra o performer como dotado de muitos tentáculos, que

Fonte: Camila Olivia de MELO [Camila Puni], 2014b. buscam elementos em diversos lugares para aderir diferentes linguagens e objetos em suas mãos-ventosas. Com essa possibilidade artística, Gui ainda reflete como a performance-polvo pode ser um "manifesto de si":

[...] acho que a grande pira da perfo... o mais forte... o mais foda... é tipo o processo... é essa alteração da própria vida e como essas coisas caminham juntas... [...] porque é o manifesto de si, né? O manifesto da pele, da carne, dos ossos, das vísceras, ao contrário do teatro... que pega um tema.

\footnotetext{
${ }^{21}$ CARLSON, 2011, p. 29, grifos nossos.
} 
A própria ação que Gui nos relata parece estar intrinsecamente ligada à atitude do corpo, ao seu movimento cotidiano, e não tanto ao texto, aos objetos ou à fala. Sendo assim, a performance, mais do que uma apresentação artística, é um momento místico, de bruxaria e ritual, o momento presente em que o performer manifesta a si mesma e exibe o seu próprio corpo. Esse corpo não normativo por vezes se liga aos códigos de feminilidade, em outros, ao de masculinidade e, na maioria do tempo, interliga-se aos modos de vida molusco marinho.

\section{Articulações finais}

O próprio corpo na performance-polvo assume especificidades que o campo de pesquisa nos trouxe, um corpo ininteligível conceituando a performance arte como potência de resistência à matriz de inteligibilidade. A partir da experiência-pesquisa, a performance arte contemporânea mostra-se também como força de alavanca crítica à cultura hegemônica, possibilitando, como foi dito, "recosturar-se" a outros elementos, comunicarse por outras linguagens e, principalmente, transgredir as barreiras do que acontece no palco, no asfalto e na carne.

A pesquisa de campo que empreendi e as percepções que tive nas entrevistas apontaram que é necessário olhar para as produções da performance arte com delicado microscópio. Em um determinado momento da observação participante, pude ouvir, sem saber de quem, a seguinte frase: "existe uma peça dentro de cada pessoa". Isso me fez pensar que cada pessoa comunica-se através da performance de uma determinada maneira. Até porque, se a intenção primeira da performance arte fosse a de emitir uma mensagem específica, uma sentença fechada ou uma ideia conclusa, não seria possível perceber tantos elementos criativos e inesperados, ou "frios na barriga", que os Estudos Queer ajudaram-me imaginativamente a encontrar.

\section{Referências}

BUTLER, Judith. "Corpos que pesam: sobre os limites discursivos do 'sexo'”. In: LOURO, Guacira Lopes. (Org.). O corpo educado: pedagogias da sexualidade. Belo Horizonte: Autêntica, 2000. p. 153-172.

Problemas de gênero: feminismo e subversão da identidade. Rio de Janeiro: Civilização Brasileira, 2012.

CARLSON, Marvin. "O que é a performance?" In: MACEDO, Ana Gabriela; RAYNER, Francesca (Org.). Gênero, cultura visual e performance: antologia crítica. Vila Nova de Famalicão: Húmus, 2011. p. 23-31.

Performance: a critical introdution. New York: Routledge, 2004.

GOLDBERG, Roselee. A arte da performance: do futurismo ao presente. São Paulo: Martins Fontes, 2006.

MELO, Camila Olivia de [Camila Puni]. A Gui - quero costurar-me novamente. Vontade de tirar uma coisa que sufoca. 2014a. Colagem em papel A4, fotocópia e material de costura. Obra "capa" da dissertação de mestrado de Camila Olivia de Melo [Camila Puni]. 2014b. Colagem em papel A4, clipes e embalagens reutilizadas.

[Recebido em outubro de 2014 e aceito para publicação em novembro de 2014] 
The Performance Art That Became Octopus: Floating in the Waters of Arts in Hybrid and Unintelligible Corporalities

Abstract: The performance in contemporary art has proved a powerful political-artistic tool to make visible corporalities at odds with heterosexual imperative. Ethnographic research was conducted for two years in a house of culture of Curitiba-PR, found body mixtures. The performance in that context was being understood as an octopus, a mixture of performance and octopus. We found a communicative power for the free expression of gender, to destabilize the coherent matrix of gender, or at least an escape from their normative and rigid models. The body tentacles give-and-take by various artistic languages to send messages, to communicate life itself, to make visible your own queer attitude.

Key Words: Performance Art; Communication; Queer. 